\title{
A Sepic Converter with Linear Transformer and Ripple Free Output for Wide Range Input Applications
}

\author{
Kirthi.C.S ${ }^{\mathbf{1}}$, Karthik.Sitapati ${ }^{2}$ \\ PG Student, Power electronics, Dayananda Sagar College of Engineering, Bangalore, India ${ }^{1}$ \\ Professor, EEE department, Dayananda Sagar College of Engineering, Bangalore, India ${ }^{2}$
}

\begin{abstract}
A linear transformer based SEPIC converter with ripple free output is proposed in this paper. The topology utilizes a linear transformer in order to obtain optimized magnetics The conventional power factor correction(PFC) single ended primary inductor converter(SEPIC) topologies proposed so far have achieved low conduction losses and reduced input ripple current but they have failed to achieve optimized magnetics.. In addition input current ripple and the voltage stresses across the switches is reduced by utilizing a clamping capacitor across the switch. A detailed analysis is carried out on MATLAB/SIMULINK platform and the various results are tabulated and analyzed. The hardware prototype model of proposed topology is designed and implemented for the input voltage of 24/55 v DC for which the expected output voltage 150v DC with the circuit efficiency of $94 \%$ is achieved.
\end{abstract}

Keywords: power electronics, power factor correction (PFC), bridgeless converter, single ended primary inductor converter (SEPIC)

\section{INTRODUCTION}

There has been an increasing demand for high power factor converters perform better at light load owing to a wide and low total harmonic distortion (THD) in the current range of choices of lower voltage rated semiconductor drawn from the utility. With the precise requirement of the devices and reduction of losses and sizes of isolation power quality, power factor correction significant efforts transformers. However, since the input current of the PFC have been made in the development of PFC converters. buck converter has dead angles during the time intervals These kinds of converters generally have full bridge diode when the input voltage, there is a strong tradeoff between rectifier on an input side so the conduction losses occur at the power factor and output voltage selection.

the input side where the full bridge diode is present. In order Therefore in order to overcome the disadvantage of the PFC to overcome this problem the full bridge diode is eliminated boost and buck converter, SEPIC converters is proposed in and bridgeless converters are introduced. The boost this paper. It is used to obtain high power factor regardless converter topology has been widely used as a PFC of its output voltage which can be stepped down or up converter because of its simplicity and high power accordingly. SEPIC converters have been adopted for many capability. It can be used with the universal input voltage applications such as high power factor correction, range. The boost converter always uses three photovoltaic system and LED lightening. However it has semiconductor voltage drops in the current flow path. To several drawbacks such as

increase the converter efficiency bridgeless boos rectifiers - High voltage stresses of power semiconductor devices were introduced. The conduction losses are reduced by $\bullet$ Low efficiency due to hard switching operation of the reducing the number of semiconductor devices that conduct current from the source to the load. However, the output diode operated in high voltage has severe reverse recovery problems due to high diode forward current and high output voltage. As the switching frequency increases,, the large reverse recovery currents of the output diodes effect the switches in the form of additional turn on losses and also produce electromagnetic interference (EMI) noises. The major disadvantage of using boost converter is that its output voltage should be higher than its peak input voltage.

Relatively low output voltage of PFC converter is required in many applications such as switched mode power supplies.

Therefore in order to overcome the disadvantages of the PFC boost converter, PFC buck converters are introduced. These converters are more suitable for many applications due to their low output voltage range. Moreover buck power switches

- Electromagnetic interference noises are significant in high-frequency operation

- A bulk inductor should be used to minimize the current ripple.

In order to overcome the above mentioned drawbacks a "Linear transformer based SEPIC converter with ripple free output for variable input application" is developed in this project. It mainly consists of a linear transformer which will overcome the disadvantage of using three magnetic components in order to reduce the current ripple and the high voltage stresses of the switches can be reduced by using a clamping capacitor across the switch.

Therefore due to the reduced ripple and voltage stresses of the power semiconductor devices the efficiency is improved. 


\section{PROPOSED TOPOLOGY}

The proposed linear transformer based SEPIC converter A. Region of operation

topology consists of a linear transformer; it is another The converter operates in three modes namely, excellent technique applied in high voltage step up applications by adjusting the turns ratio of the transformer. 1) Mode $1\left(t_{0}, t_{1}\right)$ :

The capacitor $C_{2}$ is added across the switch to reduce the During this mode the switch $S_{1}$ is turned ON, the tertiary switching losses. Diodes $\mathrm{D}_{1}$ and $\mathrm{D}_{2}$ are the input rectifiers winding of the transformer is charged and the current is and operate like a conventional SEPIC PFC converter. The induced in the primary and the secondary winding of the other components $\mathrm{C}_{1}, \mathrm{~L}_{1}, \mathrm{D}_{\mathrm{o}}$ and $\mathrm{C}_{\mathrm{o}}$ are similar to those of transformer.

conventional SEPIC converter. It is assumed that the

converter operates in discontinuous conduction mode Therefore the diode $\mathrm{D}_{1}$ is forward biased and the capacitor (DCM). The converter operation is analyzed during one $\mathrm{C}_{1}$ and the inductor $\mathrm{L}_{1}$ is charged. Hence the inductor $\mathrm{L}_{1}$ is switching period in the positive half line cycle of the input fully charged. The capacitor $\mathrm{C}_{\mathrm{o}}$ supplies to the load. The voltage. The circuit arrangement is shown in fig 1.

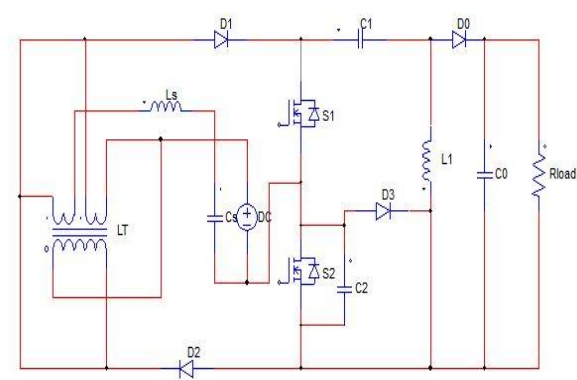

Figure 1: A linear transformer based SEPIC converter The advantages of using this topology are-

1) Closest to UPF is achieved. 2) Conversion efficiency is better compared to performing ZVS operation. others.

3) Low voltage stress across the main switch is The capacitor $\mathrm{C}_{2}$ also opposes the change in voltage. achieved by using effective clamping technique. Therefore a ripple free current is fed into the inductor $\mathrm{L}_{1}$.

4) The ripple is further reduced due to ZVS operation The current $i_{\mathrm{s}}$ decreases from its maximum value linearly as The proposed linear transformer based SEPIC converter follows operates in three modes, in one switching period. Before $t_{0}, i_{\mathrm{S}}(\mathrm{t})=\mathrm{I}_{s 1}-\frac{(1-n) V_{\text {in }}}{L_{s}}\left(t-t_{1}\right) \ldots$
the switch $\mathrm{S}_{1}$ and diode $\mathrm{D}_{\mathrm{o}}$ are turned off and the switch $\mathrm{S}_{2}$ is conducting. The theoretical waveform of the proposed converter is shown in fig 2 .

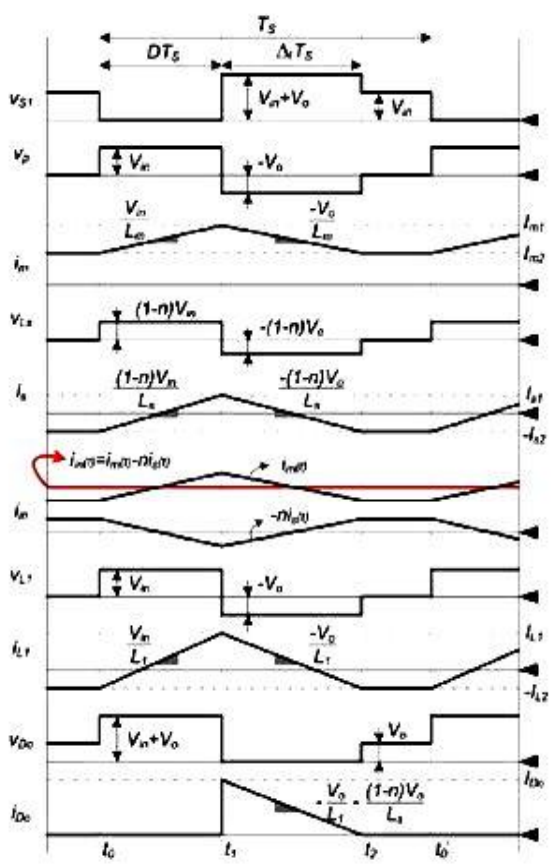

Fig. 2. Key waveforms of the proposed converte current $i_{\mathrm{s}}$ increases from its minimum value $-\mathrm{I}_{\mathrm{s} 2}$ linearly as follows.

$i_{\mathrm{S}}(\mathrm{t})=-\mathrm{I}_{s 2}+\frac{(1-n) V_{\text {in }}}{L_{s}}\left(t-t_{0}\right)$

\section{2) Mode 2( $\left.t_{1}, t_{2}\right)$ :}

During this mode the switch $S_{1}$ is turned OFF and the switch $\mathrm{S}_{2}$ is turned on. The inductor $\mathrm{L}_{1}$ which was charged previously in mode 1 will now start to discharge thus forward biasing the diode $\mathrm{D}_{\mathrm{o}}$.

The capacitor $\mathrm{C}_{\mathrm{o}}$ is fully charged and supplies the load. The capacitor $\mathrm{C}_{2}$ and diode $\mathrm{D}_{3}$ are connected across the switch $\mathrm{S}_{2}$ in order to reduce the stress across the switch $\mathrm{S}_{2}$ by

3) Mode $3\left(t_{2}, t_{0}{ }^{\prime}\right)$ :

This is a transition mode where switch $\mathrm{S}_{2}$ is about to turn off and switch $S_{1}$ to turn on. By the end of this mode the switch $\mathrm{S}_{2}$ will be turned off and switch $\mathrm{S}_{1}$ will be turned on. The output capacitor $\mathrm{C}_{\mathrm{o}}$ supplies to the load.

In all the modes of operation the diode $\mathrm{D}_{2}$ is reverse biased in order to ensure a continuous flow of current into the linear transformer and also to avoid the reverse flow of current into the switch $S_{2}$ which may cause damage to the switch

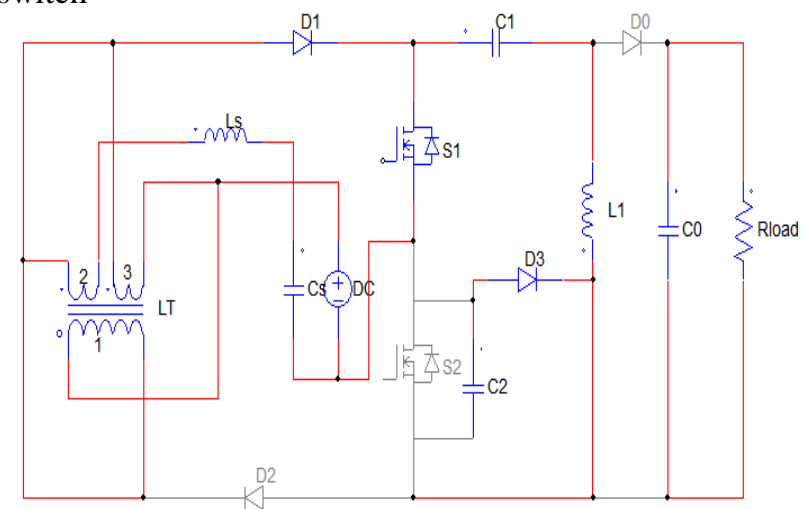

3(a) 


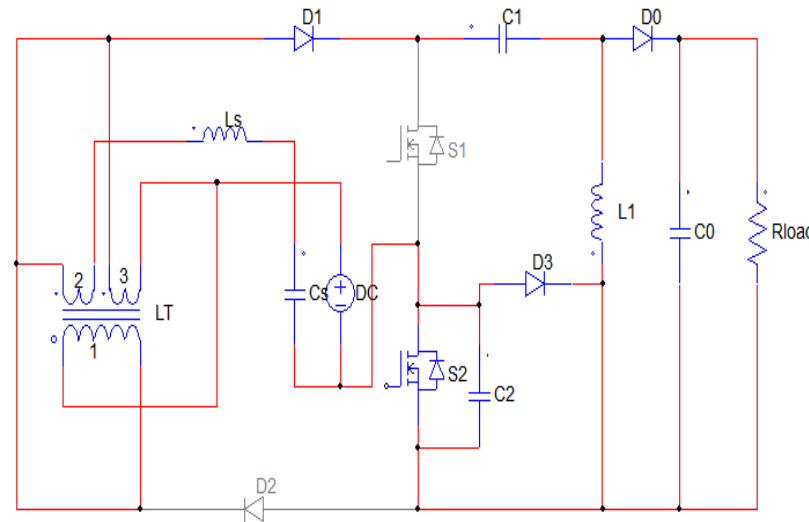

3(b)

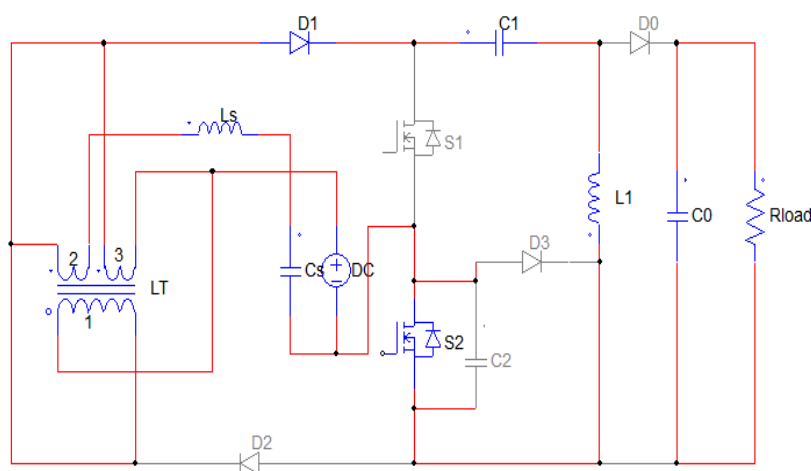

$3(\mathrm{c})$

Figure 3: shows the mode of operation of proposed circuit (a) Mode1, (b) Mode 2, (c) Mode 3

\section{DESIGN PROCEDURE}

A. Design Specification:

Design specifications of the proposed converter are as follows:

1) Main voltage $V_{\text {in }}=55 V_{d c}$;

2) DC output voltage: $V_{\mathrm{o}}=150 \mathrm{~V}$

3) Maximum output power: $P_{\text {out }}=250 \mathrm{~W}$

4) Switching frequency: $f_{\mathrm{SW}}=100 \mathrm{KHz}$

\section{B. Rating of switching devices}

In this proposed circuit, the voltage stresses of all the switching devices are equal to the sum of the maximum input voltage and output voltage as follows

$V_{D, \max }=V_{S W, \max }=V_{\text {in,peak }}+V_{o}$

The current stresses across the diode is given as follows

$\mathrm{I}_{\mathrm{D}, \max }=\mathrm{I}_{\mathrm{D} 1}=\mathrm{I}_{\mathrm{D} 2}=\left[\frac{2-\mathrm{n}}{\mathrm{l}_{\mathrm{s}}}\right] \sqrt{\frac{4 \mathrm{P}_{0} \mathrm{l}_{\mathrm{s}}}{\mathrm{f}_{\mathrm{sW}}}}$.

\section{Clamping capacitor}

As the switches conduct, they develop voltage stresses across them, thus a clamping capacitor is used across the main switch in order to reduce the stress across the switch and is given as follows.

$$
\mathrm{C}_{2}=\frac{D}{R\left(\frac{\Delta V_{o}}{V_{o}}\right) f}
$$

The voltage across the switch $S_{1}$ is same as that of the diode voltage but the voltage across the $S_{2}$ should be less when compared switch $S_{1}$ because of the clamping effect, the voltage stress across the switch $S_{1}$ is reduced

\section{$D$.Conditions to operate in DCM}

In order to guarantee that the proposed converter operate in DCM mode the inequality of $\Delta_{1}<1$ - D must be satisfied. The voltage gain can be extended greatly without an extreme duty cycle as turns ratio of the transformer increase which makes the converter suitable for high step up and high power conversion. Duty cycle is obtained as following inequality.

$$
V_{o}=\frac{1}{(1-D)} V_{\text {in }}
$$

\section{E. Average inductor current}

The average current flowing through the inductor is given as follows

$$
\begin{aligned}
\mathrm{I}_{\mathrm{L} 1} & =\frac{V_{O}^{2}}{V_{\text {in }} R} . . \\
\Delta i_{\mathrm{L} 1} & =\frac{\mathrm{V}_{\text {in }} \mathrm{D}}{\mathrm{L}_{1} \mathrm{f}} .
\end{aligned}
$$

\section{F. Output capacitor}

As the output ripple voltage is two times the input line frequency the output capacitor $\mathrm{C}_{\mathrm{o}}$ should be large enough to minimize the output voltage ripple $\Delta \mathrm{V}_{\mathrm{o}}$. Therefore, $\mathrm{C}_{\mathrm{o}}$ can be obtained from the following equation

$$
\mathrm{C}_{\mathrm{o}}=\frac{\mathrm{P}_{0}}{4 \mathrm{fV}_{0} \Delta \mathrm{V}_{\mathrm{o}}}
$$

\section{SIMULATION}

\section{A. Circuit Arrangement:}

The main aim of this project is to improve the voltage gain and efficiency and to reduce the ripple by using a linear transformer. Active clamp technique is adopted to reduce the voltage stresses. The simulation work is done in MATALB SIMULINK. The output voltage of $150 \mathrm{v}$ is obtained and simulation diagram is shown in fig 4

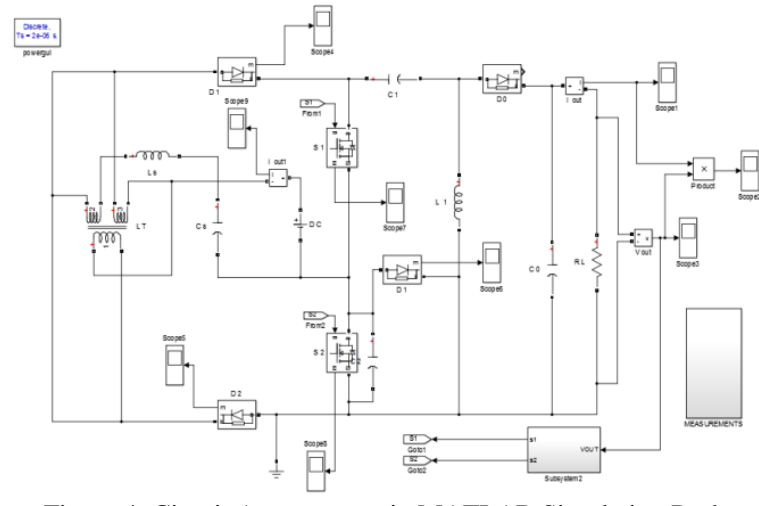

Figure 4: Circuit Arrangement in MATLAB Simulation Package

1. The fig 5 shows the proposed linear transformer based SEPIC converter for ripple free input current for a wide input range.

2. A clamping capacitor and a diode are used a cross switch $S_{2}$ for ZVS operation in order to reduce the stress

3. The value of output capacitor is reduced further so that the hardware is no more bulky

4. The waveforms of output voltage, output current and output power are shown below 


\section{Simulation Results:}

The figure 5 shows the simulation results of input voltage, output current, output power for the proposed linear transformer based SEPIC converter respectively as shown below.

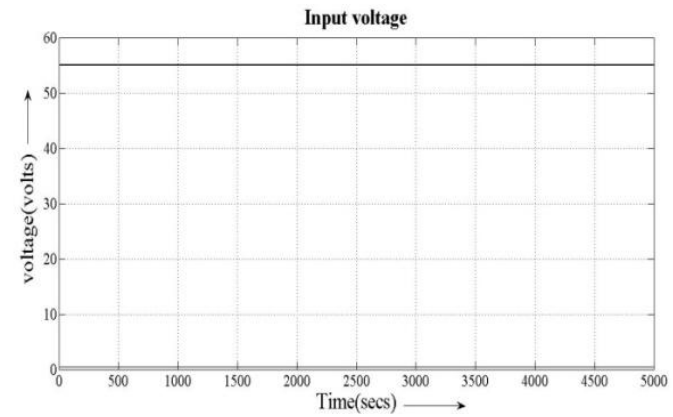

(a)

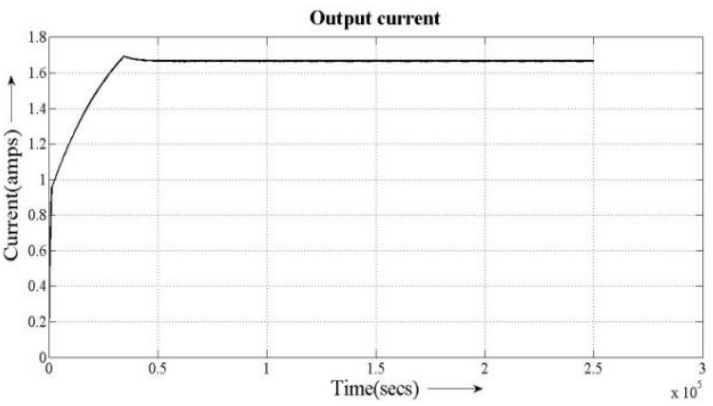

(b)

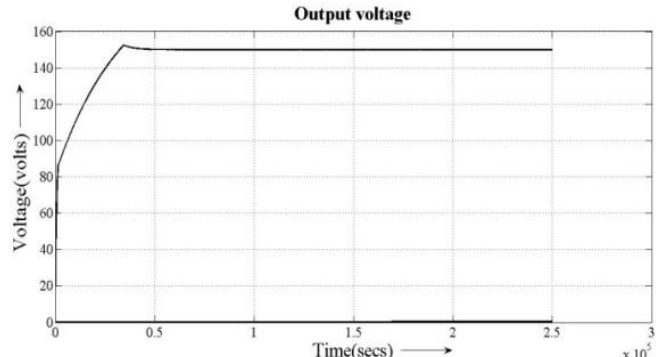

(c)

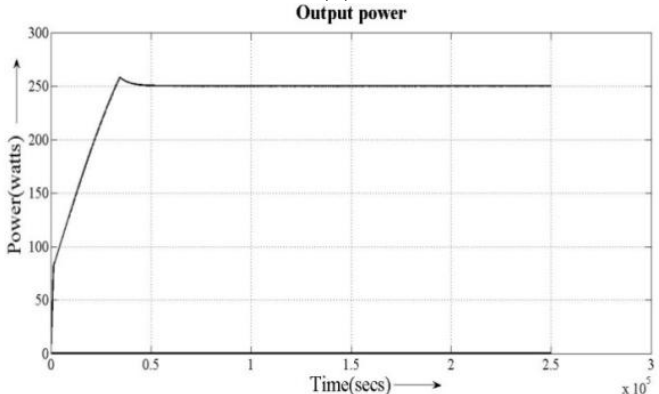

(d)

Fig 5: waveform of output voltage and output current of proposed converter.

(a) Waveform for 55V input (b) Waveform for output current (c) Waveform for $150 \mathrm{~V}$ output voltage (d) Waveform for $250 \mathrm{~W}$ output power

Figure 5(a) shows the simulation results obtained for a input voltage of $55 \mathrm{v}$.And the figure 5(b) shows the simulation results for output current of 1.6amps.And figure 5(c) shows the simulation results for output voltage $150 \mathrm{~V}$ and figure 5 (d) shows the simulation results for output power of $250 \mathrm{~W}$ which is greater than the conventional converter respectively 


\section{ACKNOWLEDGEMENT}

I would like to thank my teachers, parents and my friends for helping me out with this paper. It wouldn't have been possible without them.

\section{REFERENCES}

[1] W.-Y. Choi, J.-M. Kwon, E.-H. Kim, J.-J. Lee, and B.-H. Kwon, "Bridge-less boost rectifier with low conduction losses and reduced diode reverse-recovery problems," IEEE Trans. Ind. Electron., vol. 54, no. 2, pp. 769-780, Apr. 2007.

[2] L. Huber, Y. Jang, and M. M. Jovanovic, "Performance evaluation of bridgeless PFC boost rectifiers," IEEE Trans. Power Electron., vol. 23, no. 3, pp. 1381-1390, May 2008

[3] Y. Jang and M. M. Jovanovic, "A bridgeless PFC boost rectifier with optimized magnetic utilization," IEEE Trans. Power Electron., vol. 24, no. 1, pp. 85-93, Jan. 2009.

[4] B. Su and Z. Lu, "An interleaved totem-pole boost bridgeless rectifier with reduced reverse recovery problems for power factor correction," IEEE Trans. Power Electron., vol. 25, no. 6, pp. 1406-1415, Jun. 2010

[5] E. H. Ismail, "Bridgeless SEPIC rectifier with unity power factor and reduced conduction losses," IEEE Trans. Ind. Electron., vol. 56, no. 4, 1147-1157, Apr. 2009

[6] M. K. H. Cheung, M. H. L. Chow, and C. K. Tse, "Practical design and evaluation of a $1 \mathrm{~kW}$ PFC power supply based on reduced redundant power processing principle," IEEE Trans. Ind. Electron., vol. 55, no. 2,pp. 665-673, Feb. 2008.

[7] M. Mahdavi and H. Farzanehfard, "Bridgeless SEPIC PFC rectifier with reduced components and conduction losses," IEEE Trans. Ind. Electron., vol. 58, no. 9, pp. 4153-4160, Sep. 2011

[8] E. H. Ismail, A. J. Sabzali, and M. A. Al-Saffar, "Buck-boost-type unity power factor rectifier with extended voltage conversion ratio," IEEE Trans. Ind. Electron., vol. 55, no. 3, pp. 1123-1132, Mar. 2008.

J. P. R. Balestero, F. L. Tofoli, R. C. Fernandes, G. V. Torrico-Bascope, and F. J. M. de Seixas, "Power factor correction boost converter based on the three-state switching cell," IEEE Trans. Ind. Electron., vol. 59, no. 3,-1577, Mar. 2012A.

[9] T. J. Liang, L. S. Yang, and J. F. Chen, "Analysis and design of a singlephase ac/dc step-down converter for universal input voltage," IET Electr. Power Appl., vol. 1, no. 5, pp. 778-784, Sep. 2007.

[10] H. -L. Do, "Single-switch buck converter with a ripple-free inductor cur-rent," J. Power Electron., vol. 11, no. 4, pp. 507-511, Jul. 2011M. 